\title{
CARACTERIZAÇÃO DO LODO GERADO NUMA ESTAÇÃO DE TRATAMENTO DE ÁGUA
}

\author{
Diego Vipa AMÂNCIOㅜ; Fernando Neris RODRIGUES²; Kátia Daniela RIBEIRO³; Gilberto \\ $\mathrm{COELHO}^{4}$
}

\begin{abstract}
${ }^{1}$ Engenheiro Ambiental pelo Centro Universitário de Formiga (UNIFOR/MG). Mestre e Doutorando em Recursos Hídricos em Sistemas Agrícolas pela Universidade Federal de Lavras (UFLA). Fone: (37) 99835-0404. E-mail: diegovipa@gmail.com.

${ }^{2}$ Engenheiro Ambiental pelo Centro Universitário de Formiga (UNIFOR/MG). Mestre e Doutorando em Recursos Hídricos em Sistemas Agrícolas pela Universidade Federal de Lavras (UFLA). Fone: (37) 99949-3212. E-mail: fernandoneris99@hotmail.com.

${ }^{3}$ Engenheira Agrícola pela UFLA. Mestre e Doutora em Engenharia Agrícola pela Universidade Federal de Lavras (UFLA). Professora do Centro Universitário de Formiga (UNIFOR-MG). Fone: (37) 99983-5321. E-mail: katiadr@bol.com.br.

${ }^{4}$ Engenheiro Agrícola. Mestre e Doutor em Engenharia Agrícola pela Universidade Federal de Lavras (UFLA). Fone: (35) 3829-5273. E-mail: coelho@deg.ufla.br
\end{abstract}

Recebido em: 11/08/2017 - Aprovado em: 28/08/2017 - Disponibilizado em: 30/12/2017

Resumo: Durante o processo de potabilização da água são gerados resíduos (lodo) que, na maioria das estações de tratamento, não são tratados e são devolvidos diretamente ao manancial, impactando-o negativamente. O presente trabalho apresenta os resultados de parâmetros físico-químico-biológicos obtidos para o lodo gerado na estação de tratamento de água do Serviço Autônomo de Água e Esgoto de Formiga - MG, a fim de quantificar seu potencial poluidor. Os resultados obtidos foram confrontados com os padrões estabelecidos na Resolução $n^{\circ}$ 430/2011 do Conselho Nacional de Meio Ambiente para lançamento de efluentes em corpos receptores. O lodo da estação de tratamento de água de Formiga - MG, em ambos os períodos analisados, não atendeu à legislação, sendo indevido seu descarte direto em corpos d'água. Entretanto, as concentrações de cádmio, cálcio, chumbo, cobre, cromo, fósforo, magnésio, matéria orgânica, mercúrio, níquel, sódio e zinco no lodo não sofreram alterações dentro do intervalo de tempo analisado nesse estudo.

Palavras-chave: Resíduos. Metais pesados. Padrões de lançamento.

\section{CHARACTERIZATION OF SLUDGE GENERATED AT A WATER TREATMENT STATION}

\begin{abstract}
In the water purification process, waste (sludge) is generated and, in most treatment plants, this sludge isn't treated, being returned directly to the river, negatively impacting it. This study aimed at determining physical, chemical and biological parameters of the sludge generated at the water treatment station of the Water and Sewage Autonomous Service of the city of Formiga, Minas Gerais, Brazil, to quantify its polluting potential. Results were compared to standards established by National Environment Council, in Resolution No. 430/2011, for effluents discharge at rivers. The sludge from studied water treatment station, in both periods analyzed, didn't comply with the legislation. However, sludge's concentrations of cadmium, calcium, lead, copper, chromium, phosphorus, magnesium, organic matter, mercury, nickel, sodium and zinc didn't change within time interval analyzed in this study.
\end{abstract}

Keywords: Waste. Heavy metals. Discharge standards.

\section{INTRODUÇÃO}

Com o decorrer dos anos, a humanidade tomou proporções maiores e tanto as ciências quanto as artes evoluíram, trazendo maior conforto, comodidade e rapidez nos processos de produção, transporte e benfeitorias. Com a revolução industrial, o homem passou a utilizar máquinas, a população rural migrou para as cidades à procura de melhores condições de vida e do conforto que as novas tecnologias proporcionavam. Mas, mesmo assim, tinhase uma ideia errônea de que nenhuma 
matéria prima seria escassa e que os resíduos gerados se degradariam naturalmente (RODRIGUES, 2015).

No âmbito mundial atual, onde as cidades são assustadoramente grandes e as escalas de consumo e produção são igualmente extraordinárias, a humanidade luta para preservar seus recursos naturais e tentar amenizar os impactos causados pela maciça exploração das fontes naturais de matéria prima (AMÂNCIO, 2012).

Com o aumento da população nos centros urbanos, aumentou-se, consequentemente, a demanda por serviços em vários setores; um dos setores mais afetados foi o do saneamento básico (LIMA et al., 2016). E muitas cidades ainda não possuem estruturas adequadas e suficientes para atender a essa demanda de consumidores, causando muitos impactos no meio ambiente (VIANA et al., 2014).

Assim, com o aumento da demanda de água potável, mais recursos hídricos têm de ser extraídos para os devidos processos de tratamento, sendo que em todos esses processos são gerados resíduos (AMÂNCIO, 2012).

O lodo produzido durante o processo de potabilização da água numa Estação de Tratamento de Água (ETA) é constituído de resíduos sólidos orgânicos e inorgânicos (argilas e areias) provenientes da água bruta e principalmente grandes concentrações de metais, decorrentes da adição de produtos químicos e polímeros condicionantes do processo (BARBOSA et al., 2000).

O lodo de ETA é gerado, normalmente, em grandes quantidades e diariamente, visto que todo dia há a demanda por água tratada (OLIVEIRA, 2016). E o fato de muitas ETA's lançaremno diretamente nos rios, causando um impacto na biodiversidade dos mesmos (ACHON et al., 2013), fez com que pesquisadores voltassem à atenção para tal fato na tentativa de desenvolver estudos para caracterização e avaliação dos impactos causados por sua destinação direta em cursos d'água (ANDREOLI, 2001; BARROSO; CORDEIRO, 2001; GONÇALVES, 1997).

Caracterizar esse resíduo é, portanto, de suma importância para propor alternativas corretas para sua disposição final, reduzindo o impacto causado pelo seu lançamento indevido nos cursos d'água.

Assim sendo, objetivou-se nesse trabalho realizar a caracterização física, química e biológica do lodo gerado na ETA do Serviço Autônomo de Água e Esgoto (SAAE) do município de Formiga - MG, permitindo quantificar seu potencial poluidor para corpos hídricos receptores.

\section{MATERIAL E MÉTODOS}

O objeto de estudo foi o lodo gerado na ETA do SAAE do município de Formiga 
- MG, para o qual foram avaliados parâmetros físicos, químicos e biológicos de caracterização. A referida cidade tem como concessionária de saneamento básico o SAAE, que foi inaugurado em 27 de dezembro de 1971, quando a cidade passou a contar com água tratada e esgoto encanado.

A ETA do SAAE de Formiga - MG é do tipo convencional e tem capacidade de tratar $17.280 \mathrm{~m}^{3}$ por dia. O processo convencional de tratamento de água para abastecimento humano, segundo Botero (2009), é aquele que emprega a sedimentação com o uso de coagulantes e compreende as etapas unitárias de coagulação, floculação, decantação e filtração, para a clarificação da água, seguidas da correção do pH, desinfecção e fluoretação.

A captação de água é realizada fora do perímetro urbano, no Rio Formiga, que pertence à bacia do Rio Grande. A ETA do SAAE de Formiga - MG conta com um floculador dividido em quatros baias de floculação, dois decantadores, quatro filtros, um reservatório de água tratada com capacidade de $1.000 \mathrm{~m}^{3}$ e outro para lavação dos filtros com capacidade de $65 \mathrm{~m}^{3}$.

O coagulante utilizado na ETA do SAAE de Formiga - MG é o sulfato de alumínio ferroso líquido, cuja empresa fornecedora é a Suall Indústria e Comércio LTDA. A Tabela 1 apresenta a composição desse coagulante.

Tabela 1. Composição do coagulante utilizado na ETA do SAAE de Formiga - MG.

\begin{tabular}{cccc}
\hline Análise & Especificação & Resultado & U.M. \\
\hline Alumino Solúvel em Água como $\mathrm{Al}_{2} \mathrm{O}_{3}$ & 7,500 à 9,000 & 7,890 & $\%$ \\
Ferro Total Solúvel $\mathrm{Fe}_{2} \mathrm{O}_{3}$ & 0,000 à 1,200 & 0,986 & $\%$ \\
Alcalinidade Livre como $\mathrm{Al}_{2} \mathrm{O}_{3}$ & 0,000 à 0,400 & 0,000 & $\%$ \\
Acidez livre como $\mathrm{H}_{2} \mathrm{SO}_{4}$ & 0,000 à 0,500 & 0,217 & $\%$ \\
Resíduo Insolúvel em Água & 0,000 à 0,050 & 0,008 & $\%$ \\
Densidade & 1,300 à 1,350 & 1,315 & g. $\mathrm{mL}^{-1}$ \\
\hline
\end{tabular}

Nota: U.M.= unidade de medida

Fonte: Suall Indústria e Comércio LTDA (2012).

Para fins de caracterização, trabalhou-se com o lodo gerado nos decantadores da ETA, pois nos mesmos

No SAAE, o lodo fica detido nos decantadores por um período que pode ocorre a remoção de cerca de 60 a 70\% de todos os sólidos presentes na água bruta durante o processo de clarificação. variar de um a quatro meses, dependendo da época do ano em relação a períodos 
chuvosos ou secos. Quando o SAAE faz a lavagem dos seus decantadores, lança todo esse lodo diretamente no Rio Formiga.

As amostras do lodo foram coletadas em um dos decantadores, em períodos distintos: uma amostragem foi realizada no dia 29 de junho de 2011 e a segunda amostragem foi realizada no dia 10 de abril de 2012.

O lodo gerado nos decantadores apresenta elevada umidade (cerca de 90\%), então, para sua caracterização, foi realizada a desidratação do mesmo, como mostra a Figura 1.

Figura 1. Desidratação do lodo gerado nos decantadores da ETA do SAAE de Formiga - MG.

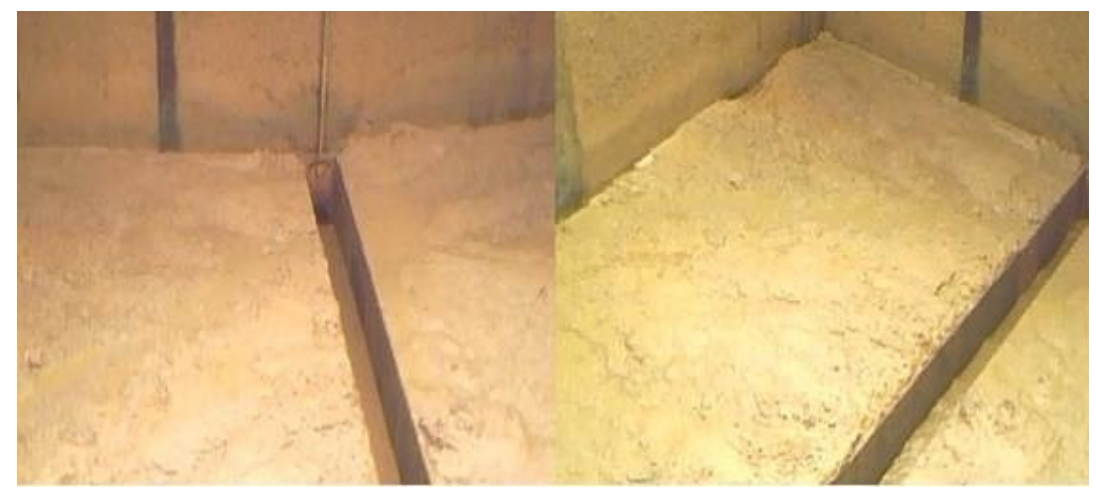

Fonte: Autoria própria.

Adotou-se para esse fim um leito de secagem do tipo convencional, construído utilizando-se um reservatório de polietileno de 2.000 litros, tubos de PVC de $50 \mathrm{~mm}$; o meio filtrante foi constituído por três tamanhos de britas distintas (números um, dois e três), areia grossa e tijolos furados. A Figura 2 apresenta o desenho esquemático do leito de secagem e a Figura 3 apresenta detalhes construtivos do mesmo.

Figura 2. Desenho esquemático do leito de secagem.

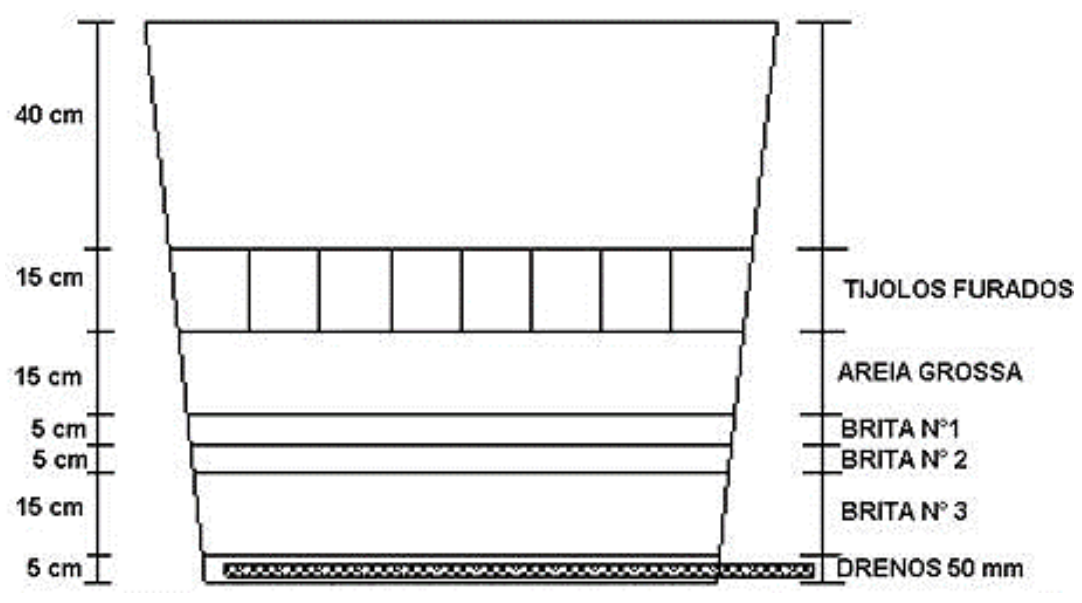

Fonte: Autoria própria. 
Figura 3. Detalhes construtivos do leito de secagem.

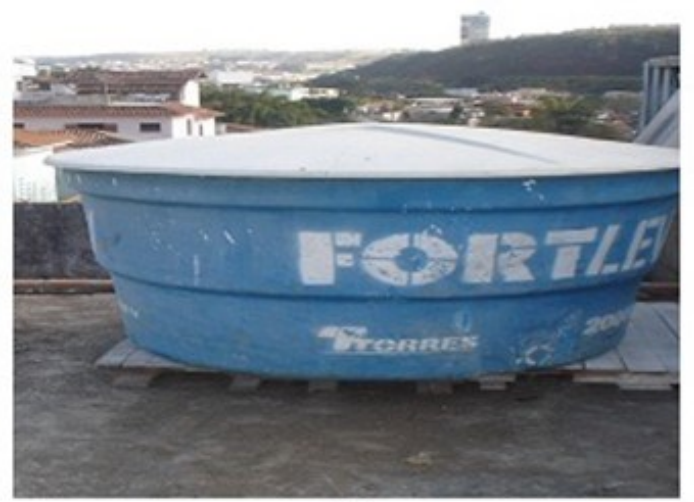

a)

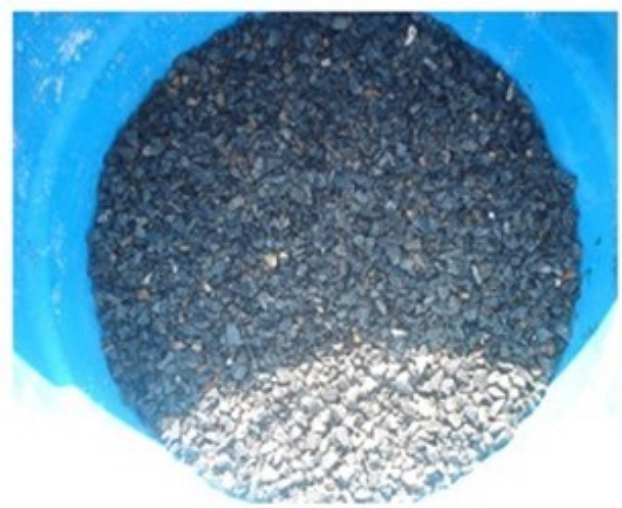

c)

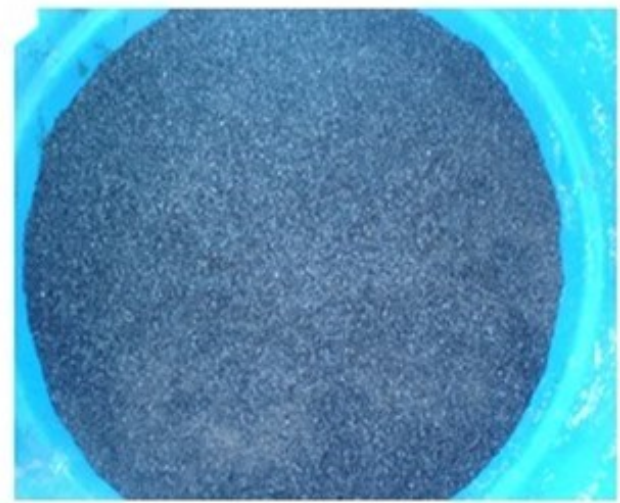

e)

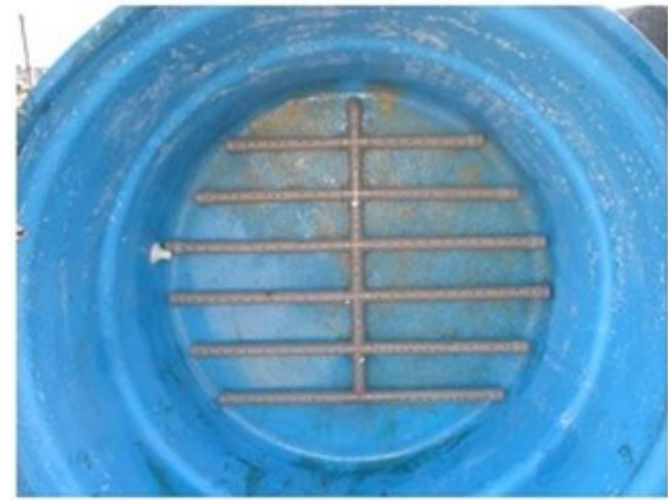

b)

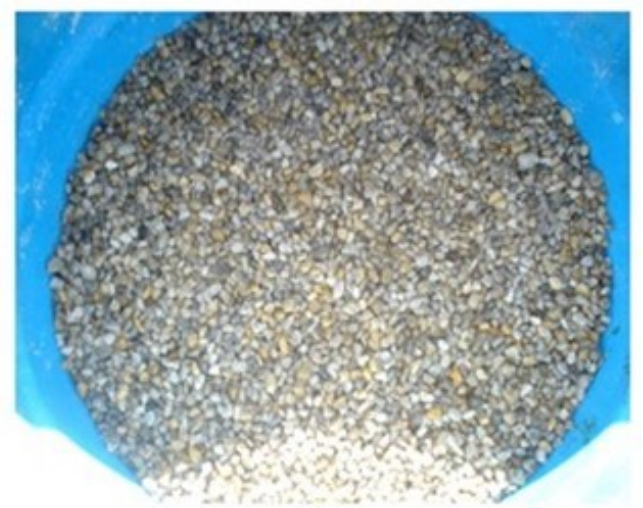

d)

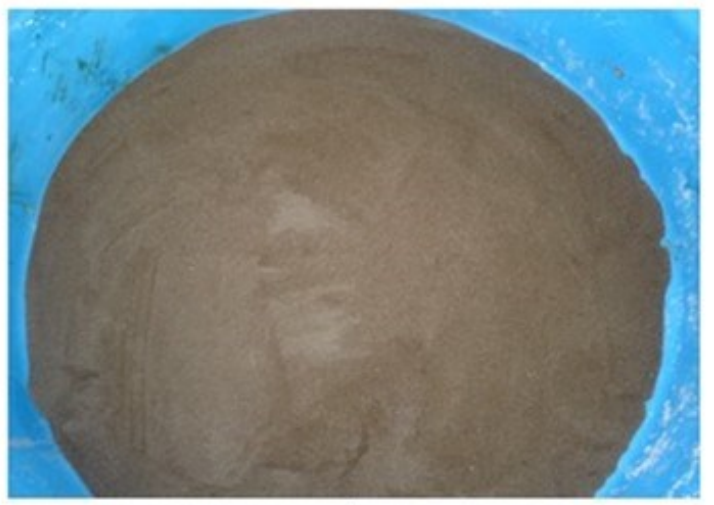

f)

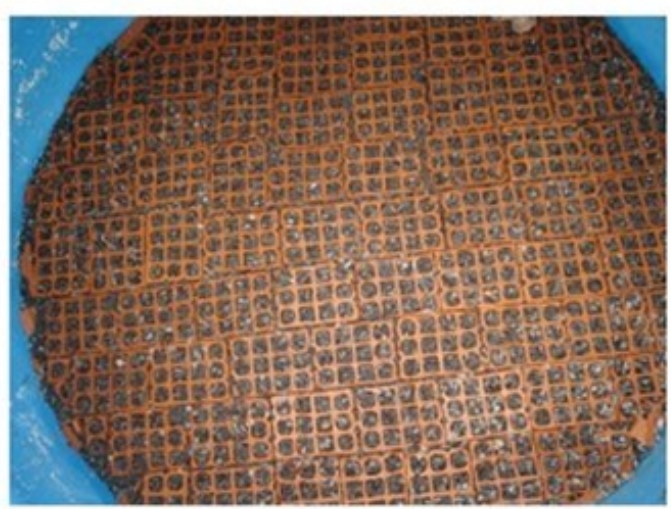

g)

Nota: a) Caixa de $2 \mathrm{~m}^{3}$; b) Drenos de canos e conexões de $50 \mathrm{~mm}$; c) Brita $\mathrm{n}^{\circ} 3$; d) Seixo $\mathrm{n}^{\circ} 2$; e) Brita $\mathrm{n}^{\circ}$ 1; f) Areia Grossa; g) Tijolos furados com britas $n^{\circ} 1$.

Fonte: Autoria própria. 
Uma vez coletadas, as amostras de lodo desidratado foram encaminhadas para Nova Ambi Serviços Analíticos Ltda, localizada em São Paulo - SP, para determinação dos parâmetros de caracterização, com três repetições. Os parâmetros analisados foram:

a) Físicos: densidade, determinada conforme Ministério da Agricultura, Pecuária e Abastecimento (MAPA, 2007); sólidos totais e umidade, determinados conforme American Public Health Association (APHA, 2005).

b) Químicos: alumínio, cádmio, cálcio, chumbo, cobre, cromo, ferro, fósforo, magnésio, manganês, níquel, nitrogênio, sódio, potássio e zinco foram determinados conforme APHA (2005); carbono, determinado conforme Agência de Proteção Ambiental dos Estados Unidos (Environmental Protection Agency - EPA, 1983); enxofre, determinado conforme EPA (1996); matéria orgânica, determinada conforme EPA (1998a); mercúrio, determinado conforme EPA (1998b); e potencial hidrogeniônico $(\mathrm{pH})$, determinado conforme EPA (2004).

c) Biológicos: coliformes totais e termotolerantes, determinados conforme APHA (2005).

De posse dos resultados disponibilizados pelo laboratório, os mesmos foram submetidos ao teste de Tukey para comparação de médias, segundo delineamento inteiramente casualizado, a um nível de significância de 5\% $(\alpha=0,05)$. Esse teste de média foi feito utilizando o programa de análise estatística SISVAR (FERREIRA, 2008).

Avaliou-se ainda a carga poluidora do lodo gerado na ETA do SAAE de Formiga MG, confrontando os parâmetros de sua caracterização com os padrões estabelecidos pela Resolução do Conselho Nacional do Meio Ambiente - CONAMA 430/2011. Para tanto, foi necessário realizar a conversão dos resultados dos parâmetros analisados.

Os resultados foram fornecidos pelo laboratório contratado em $\mathrm{mg}$ do parâmetro por $\mathrm{kg}$ de lodo analisado. Porém, para comparar as concentrações dos parâmetros com os padrões da resolução CONAMA 430/2011, os parâmetros devem ser expressos em mg do parâmetro por litro de resíduo.

Conhecendo-se a densidade do resíduo, foi possível estabelecer a relação entre massa e volume do mesmo, o que possibilitou a conversão das unidades $\mathrm{mg} / \mathrm{kg}$ de lodo para $\mathrm{mg} / \mathrm{L}$ de lodo através da Equação 1 .

$\mathrm{C}_{2}=\mathrm{C}_{1} . \mathrm{D}$

em que:

$\mathrm{C}_{1}=$ concentração do parâmetro analisado $\mathrm{em} \mathrm{mg} / \mathrm{kg}$;

$\mathrm{C}_{2}=$ concentração do parâmetro analisado em $\mathrm{mg} / \mathrm{L}$;

$\mathrm{D}=$ densidade do lodo em $\mathrm{g} / \mathrm{cm}^{3}$. 
RESULTADOS E DISCUSSÃO

A Tabela 2 apresenta os resultados da caracterização do lodo gerado na ETA do SAAE de Formiga- MG. Observa-se que as concentrações de cádmio, cálcio, chumbo, cobre, cromo, fósforo, magnésio, matéria orgânica, mercúrio, níquel, sódio e zinco não diferiram estatisticamente para as duas amostragens realizadas.

Tabela 2. Valores médios dos parâmetros físicos, químicos e biológicos do lodo gerado na ETA do SAAE de Formiga - MG.

\begin{tabular}{lcc}
\hline Parâmetro & $\begin{array}{c}\text { Amostragem } 01 \\
\text { Junho/2011 }\end{array}$ & $\begin{array}{c}\text { Amostragem } 02 \\
\text { Abril/2012 }\end{array}$ \\
\hline Alumínio Total $(\mathrm{mg} / \mathrm{kg})$ & $119000 \mathrm{a}$ & $71666 \mathrm{~b}$ \\
Cádmio Total $(\mathrm{mg} / \mathrm{kg})$ & $0,66 \mathrm{a}$ & $0,70 \mathrm{a}$ \\
Cálcio Total $(\mathrm{mg} / \mathrm{kg})$ & $<5,0 \mathrm{a}$ & $<5,0 \mathrm{a}$ \\
Chumbo Total $(\mathrm{mg} / \mathrm{kg})$ & $50,57 \mathrm{a}$ & $50,70 \mathrm{a}$ \\
Cobre $(\mathrm{mg} / \mathrm{kg})$ & $14,39 \mathrm{a}$ & $10,25 \mathrm{a}$ \\
Termotolerantes $(\mathrm{NMP} / 25 \mathrm{~g})$ & $<1,1 \mathrm{~b}$ & $8433,3 \mathrm{a}$ \\
Coliformes Totais $(\mathrm{NMP} / 25 \mathrm{~g})$ & $<1,1 \mathrm{~b}$ & $25000,0 \mathrm{a}$ \\
Cromo Total $(\mathrm{mg} / \mathrm{kg})$ & $11,7 \mathrm{a}$ & $21,0 \mathrm{a}$ \\
Densidade $\left.(\mathrm{g} / \mathrm{cm})^{3}\right)$ & $1,16 \mathrm{a}$ & $0,94 \mathrm{~b}$ \\
Enxofre Total $(\mathrm{mg} / \mathrm{kg})$ & $349,3 \mathrm{a}$ & $0,0 \mathrm{~b}$ \\
Ferro Total $(\mathrm{mg} / \mathrm{kg})$ & $46966,7 \mathrm{a}$ & $27700,0 \mathrm{~b}$ \\
Fósforo Total $(\mathrm{mg} / \mathrm{kg})$ & $90,63 \mathrm{a}$ & $110,67 \mathrm{a}$ \\
Magnésio Total $(\mathrm{mg} / \mathrm{kg})$ & $172,0 \mathrm{a}$ & $116,3 \mathrm{a}$ \\
Manganês Total $(\mathrm{mg} / \mathrm{kg})$ & $303,3 \mathrm{a}$ & $66,7 \mathrm{~b}$ \\
Matéria Orgânica $(\%)$ & $12,97 \mathrm{a}$ & $10,04 \mathrm{a}$ \\
Mercúrio Total $(\mathrm{mg} / \mathrm{kg})$ & $0,07 \mathrm{a}$ & $0,05 \mathrm{a}$ \\
Níquel Total $(\mathrm{mg} / \mathrm{kg})$ & $17,84 \mathrm{a}$ & $9,84 \mathrm{a}$ \\
Nitrogênio Total $(\mathrm{mg} / \mathrm{kg})$ & $3986,7 \mathrm{a}$ & $1180,0 \mathrm{~b}$ \\
Ph & $6,7 \mathrm{~b}$ & $8,1 \mathrm{a}$ \\
Potássio Total $(\mathrm{mg} / \mathrm{kg})$ & $472,0 \mathrm{~b}$ & $948,7 \mathrm{a}$ \\
Sódio Total $(\mathrm{mg} / \mathrm{kg})$ & $454,0 \mathrm{a}$ & $50,3 \mathrm{a}$ \\
Sólidos Secos a $105^{\circ} \mathrm{C}(\%)$ & $37,2 \mathrm{~b}$ & $3870,0 \mathrm{~b}$ \\
Carbono Orgânico Total $(\mathrm{mg} / \mathrm{kg})$ & $20000,0 \mathrm{a}$ & $49,7 \mathrm{~b}$ \\
Umidade a $105^{\circ} \mathrm{C}(\%)$ & $62,7 \mathrm{a}$ & $\mathrm{a}$ \\
Zinco Total $(\mathrm{mg} / \mathrm{kg})$ & $53,4 \mathrm{a}$ & \\
\hline & & \\
\hline
\end{tabular}

Nota: Médias seguidas pela mesma letra nas linhas não diferem pelo teste de Tukey a 5\% de probabilidade. Fonte: Dados da pesquisa. 
A menor concentração de alumínio verificada na segunda amostragem pode estar relacionada com a vazão da água durante o tratamento. Silva; Xavier (2008) verificaram variações significativas entre a concentração de alumínio em lodo de ETA e a vazão de entrada da água no sistema de tratamento.

Segundo Santos; Garcia (2016), a estação chuvosa no estado de Minas Gerais tem início no mês de outubro, com término no mês de maio. Na estação chuvosa, a água bruta chega mais turva à ETA e há a necessidade do uso de mais coagulante. Entretanto, além de mais turva, a água bruta chega à ETA com maior vazão, gerada pelo aumento dos eventos pluviométricos.

Silva; Xavier (2008) explicam que o aumento da dosagem de coagulante utilizada no período chuvoso nem sempre é proporcional ao aumento da vazão de entrada da água bruta. Avaliando os teores de alumínio no efluente da ETA de Anápolis - GO, os autores constataram que quando a vazão da água de entrada aumenta, menor é a concentração de alumínio no lodo.

A mesma justificativa pode ser aplicada aos menores teores de ferro e enxofre encontrados para a segunda amostragem, visto que estes elementos, juntamente com o alumínio, são os principais constituintes do coagulante utilizado na ETA do SAAE de Formiga MG.

As maiores concentrações tanto de coliformes termotolerantes quanto totais foram verificadas para o lodo gerado na segunda amostragem. Nesse período, a água bruta chega para captação altamente turva, conforme já mencionado, e essa turbidez origina-se, geralmente, do arraste de partículas sólidas do solo pelo escoamento superficial das chuvas. Junto com as partículas do solo, pode ser carreada matéria orgânica constituinte do próprio solo ou de fezes animais, provocando o incremento de coliformes na água bruta. Esse resultado remete ao maior tempo, cuidado e também maiores quantidades de reagentes em geral que precisam ser usados para controlar o tratamento da água no período chuvoso, a fim de garantir sua potabilidade quanto aos parâmetros biológicos, visto que os mesmos se constituem em veículos de doenças. Em contrapartida, há de se ressaltar que os coliformes presentes na água bruta são eliminados na fase da desinfecção que, de um modo geral, é realizada através da adição de cloro à água. $\mathrm{O}$ aumento da adição de cloro nos processos de desinfecção da água aumenta o potencial de formação de trihalometanos, que são compostos prejudiciais à saúde.

As maiores concentrações de manganês, nitrogênio e carbono foram 
encontradas para o lodo da primeira amostragem, que ocorreu no período seco, conforme Santos; Garcia (2016). A menor vazão do rio associada à baixa pluviosidade reduz a capacidade de diluição do curso d'água. Logo, as concentrações desses elementos na água bruta, na primeira amostragem, elevam-se, sendo removidos durante o processo de coagulação, passando a fazer parte do lodo da ETA.

Contrariamente ao manganês, nitrogênio e carbono, as concentrações de potássio apresentaram-se maior no lodo gerado na segunda amostragem. Uma vez que esse elemento não é um constituinte do coagulante usado, sua origem no lodo advém das características da própria água bruta. Verifica-se que sua concentração praticamente duplicou da primeira para a segunda amostragem, permitindo inferir que esse aumento se deve a alguma fonte de contaminação da água bruta a montante da captação que está provocando o aumento de sua concentração na mesma e, consequentemente, no lodo.

Richter; Azevedo Netto (2003) dizem que, do ponto de vista analítico, o $\mathrm{pH}$ é um dos parâmetros mais importantes na determinação da maioria das espécies químicas de interesse tanto da análise de águas potáveis como na análise de águas residuárias, sendo, pois, uma das mais comuns e importantes determinações no contexto da química da água. No campo do abastecimento de água, o $\mathrm{pH}$ intervém na coagulação química, controle da corrosão, abrandamento e desinfecção. Águas com baixos valores de $\mathrm{pH}$ tendem a ser agressivas para instalações metálicas. Segundo Leal (2009), a faixa ideal para aplicação do sulfato de alumínio, para ter uma boa coagulação, é de 5,0 a 8,0 ; fora desta faixa, o processo não é eficiente.

Uma vez que a aplicação de sulfato de alumínio ferroso tende a diminuir o $\mathrm{pH}$ do meio com o aumento de sua aplicação, e que os lodos gerados, ao terem seu $\mathrm{pH}$ analisado, já haviam tido contato com o coagulante, era de se esperar um menor $\mathrm{pH}$ para o lodo da segunda amostragem, cuja água bruta tende a receber maior quantidade de sulfato de alumínio no processo de coagulação. Entretanto, isso não ocorreu. Provavelmente não há correção de $\mathrm{pH}$ na ETA do SAAE de Formiga - MG a montante dos decantadores, ou ainda podese inferir que a água bruta no período que antecedeu a segunda amostragem apresenta-se naturalmente mais básica que no período antecessor à primeira amostragem, o que precisaria ser confirmado por análises da água bruta e que não correspondeu aos objetivos deste trabalho.

Numa amostra de lodo, a quantidade de sólidos e a umidade são inversamente proporcionais, ou seja, quanto mais úmido o material, menor a 
porcentagem de sólidos na amostra, e viceversa. Assim, observa-se que o lodo desidratado referente à segunda amostragem apresentou maior concentração de sólidos secos (totais), evidenciando que o processo de desidratação do lodo foi mais eficiente nessa amostragem que na primeira. Se a concentração de sólidos foi maior na segunda amostragem, consequentemente, a umidade do lodo desidratado foi menor para este período.

Em ambas as amostragens, o lodo coletado nos decantadores ficou detido no leito de secagem por 30 dias. Apesar da não ocorrência de chuvas nesse período para o lodo da primeira amostragem, que poderia caracterizar em incremento de umidade, as temperaturas nessa época do ano são mais amenas, dificultando a evaporação da água, ficando o processo de desidratação restrito à percolação do excesso de umidade. Na segunda amostragem, as temperaturas mais elevadas favorecem a evaporação que, associada à percolação, removem com maior eficiência a água do material. Cabe ressaltar que, em ambos os períodos, os leitos de secagem foram mantidos protegidos contra eventuais precipitações.
Os dados apresentados na Tabela 3 permitem avaliar o enquadramento ou não do lodo gerado na ETA do SAAE de Formiga - MG à legislação pertinente ao lançamento de resíduos em corpos receptores.

O único parâmetro que atendeu à legislação, em ambas amostragens, foi o pH. Todos os demais parâmetros não atenderam à legislação, caracterizando o lodo da ETA do SAAE de Formiga - MG como altamente poluidor para o Rio Formiga, seu atual destino final.

Cabe ressaltar que a Resolução CONAMA 430/2011 não apresenta valores limites para todos os parâmetros analisados, dentre eles o alumínio, que foi o elemento que predominou na composição química do lodo estudado, apresentando concentração muito alta. Nesse caso, ressalta-se que, principalmente quanto ao alumínio, sua toxidez está mais relacionada à sua solubilidade do que à sua concentração, o que implica em estudos adicionais nesse sentido quanto ao lodo da ETA do SAAE de Formiga - MG.

$\mathrm{O}$ chumbo tem um efeito adverso por ser um metal pesado e tem um efeito tóxico na biota muito grande. Nas pessoas, causa a doença denominada saturnismo (KLAASSEN, 1991). 
Tabela 3. Caracterização do lodo da ETA do SAAE de Formiga - MG e confrontação com a legislação.

\begin{tabular}{|c|c|c|c|}
\hline Parâmetro & $\begin{array}{c}\text { Amostragem } 01 \\
\text { Junho/2011 }\end{array}$ & $\begin{array}{c}\text { Amostragem } 02 \\
\text { Abril } / 2012\end{array}$ & $\begin{array}{c}\text { Padrão de } \\
\text { lançamento de } \\
\text { efluente }\end{array}$ \\
\hline Alumínio Total (mg/kg) & 119000 & 71666 & - \\
\hline Cádmio Total (mg/L) & 0,77 & 0,66 & $0,2 \mathrm{mg} / \mathrm{L}$ \\
\hline Cálcio Total (mg/kg) & $<5,0$ & $<5,0$ & - \\
\hline Chumbo Total (mg/L) & 58,66 & 47,66 & $0,5 \mathrm{mg} / \mathrm{L}$ \\
\hline Cobre $(\mathrm{mg} / \mathrm{L})$ & 16,69 & 9,64 & $1,0 \mathrm{mg} / \mathrm{L}$ \\
\hline Termotolerantes (NMP/25g) & $<1,1$ & 8433,3 & - \\
\hline Coliformes Totais (NMP/25g) & $<1,1$ & 25000,0 & - \\
\hline Cromo Total (mg/L) & 13,57 & 19,74 & $1,0 \mathrm{mg} / \mathrm{L}$ \\
\hline Enxofre Total (mg/kg) & 349,3 & 0,0 & - \\
\hline Ferro Total (mg/L) & 54481,37 & 26038,00 & $15 \mathrm{mg} / \mathrm{L}$ \\
\hline Fósforo Total (mg/kg) & 90,63 & 110,67 & - \\
\hline Magnésio Total (mg/kg) & 172,0 & 116,3 & - \\
\hline Manganês Total (mg/L) & 351,83 & 62,70 & $1,0 \mathrm{mg} / \mathrm{L}$ \\
\hline Matéria Orgânica (\%) & 12,97 & 10,04 & - \\
\hline Mercúrio Total (mg/L) & 0,08 & 0,05 & $0,01 \mathrm{mg} / \mathrm{L}$ \\
\hline Níquel Total (mg/L) & 20,69 & 9,25 & $2,0 \mathrm{mg} / \mathrm{L}$ \\
\hline Nitrogênio Total (mg/L) & 4624,57 & 1109,20 & $20,0 \mathrm{mg} / \mathrm{L}$ \\
\hline $\mathrm{pH}$ & 6,7 & 8,1 & Entre 5 e 9 \\
\hline Potássio Total (mg/kg) & 472,0 & 948,7 & - \\
\hline Sódio Total (mg/kg) & 454,0 & 111,3 & - \\
\hline Sólidos Secos a $105^{\circ} \mathrm{C}(\%)$ & 37,2 & 50,3 & - \\
\hline Carbono Orgânico Total (mg/kg) & 20000,0 & 3870,0 & - \\
\hline Umidade a $105^{\circ} \mathrm{C}(\%)$ & 62,7 & 49,7 & - \\
\hline Zinco Total (mg/L) & 61,94 & 40,51 & $5,0 \mathrm{mg} / \mathrm{L}$ \\
\hline
\end{tabular}

Nota: Padrão de lançamento de efluentes em corpos hídricos segundo Resolução CONAMA 430/2011. Fonte: Dados da pesquisa.

O efeito adverso do cobre nos corpos d'água pode trazer sérias consequências. Assim como os demais metais pesados, o cobre é transportado pelo sangue ligado a proteínas, geralmente a ceruloplasmina (HEATH, 1995), podendo gerar problemas de crescimento, anormalidades corporais, aumento no tamanho dos ovos, aumento na mortalidade de embriões (HEATH, 1984; 1995; HANSEN et al., 2002), alterações histopatológicas nas brânquias e fígado (MAZON et al., 1999; KARAN et al., 1998; CERQUEIRA; FERNANDES， 2002; 
MAZON et al., 2002), distúrbios na regulação iônica (LAURÉN; MCDONALD, 1987; MCGEER et al., 2000ab), peroxidação lipídica (ROMÉO et al., 2000) e distúrbios hematológicos (NUSSEY et al., 1995ab).

$\mathrm{O}$ ferro em altas concentrações provoca, juntamente com o manganês, principalmente, alterações na cor e no sabor da água. Em termos de água para abastecimento, o ferro deve ser muito bem monitorado, pois a cor e o sabor inadequados implicam em rejeição da água pela sociedade, além do excesso de ferro na água poder se depositar nas canalizações de distribuição.

O mercúrio é um elemento químico considerado não essencial a qualquer processo metabólico; entretanto, é facilmente acumulado na maioria dos organismos. Ocorre naturalmente em formas orgânicas e inorgânicas, não só no estado sólido ou dissolvido, mas também na fase gasosa. Consequentemente, seu ciclo biogeoquímico envolve processos que ocorrem no solo, na água e na atmosfera (WINDMÖLLER et al., 2007).

O mercúrio pode ser depositado nos solos e em corpos d'água naturalmente, em períodos de tempos relativamente longos, e o acúmulo desse elemento pode acarretar sérios danos (AZEVEDO, 2003).

No meio aquático, o mercúrio pode ser encontrado na água propriamente dita e nos sedimentos. Ao atingirem os ambientes aquáticos, as espécies inorgânicas do mercúrio podem sofrer reações mediadas, principalmente, por microrganismos que alteram seu estado inicial, resultando em compostos organomercuriais como o metilmercúrio, mais tóxico do que as espécies inorgânicas. O metilmercúrio é facilmente absorvido por peixes e outros animais aquáticos, o que leva à deposição dessa substância nos tecidos, acumulandose ao longo do tempo e atingindo, na cadeia biológica, concentrações bem maiores do que as encontradas nas águas e nos sedimentos (AZEVEDO, 2003).

O nitrogênio chega aos ambientes aquáticos através das chuvas, fixação biológica e origem alóctone. Portanto, os níveis de concentração das formas dissolvidas são influenciados pelo tipo de vegetação e atividades no seu entorno (SILVA, 2005).

O zinco é considerado um micronutriente essencial para $\mathrm{o}$ desenvolvimento das plantas, porém, em concentrações elevadas torna-se tóxico. De acordo com a Universidade Federal de Campina Grande - UFCG (2012), uma vez que os rios deságuam no mar, estes poluentes (metais pesados, como nitrogênio, zinco, níquel, cobre, entre outros) podem alcançar as águas salgadas e, em parte, depositar-se no leito oceânico. Além disso, os metais contidos nos tecidos 
dos organismos vivos que habitam os mares acabam também se depositando, cedo ou tarde, nos sedimentos, representando um estoque permanente de contaminação para a fauna e a flora aquáticas.

De acordo com os resultados obtidos, notou-se que a quantidade de metais pesados existente nas amostras de lodo coletadas evidencia que seu descarte direto em cursos d'água, como habitualmente vem sendo feito pelas concessionárias de abastecimento, é bastante danoso para o meio ambiente. Assim, a destinação final desse resíduo deve ser reavaliada pelas concessionárias, de modo a garantir a integridade dos recursos hídricos, que se constituem na principal matéria-prima das mesmas. Portanto, o melhor destino final para o lodo da ETA do SAAE de Formiga - MG seriam os aterros sanitários, em função de suas características físicas, químicas e biológicas aqui constatadas e perante a averiguação de seu alto potencial poluidor para os cursos hídricos.

Alternativas de seu reaproveitamento também podem ser estudadas, de maneira promover a sustentabilidade do processo de tratamento de águas para abastecimento; porém, essas alternativas necessitam ser estudadas.

\section{CONCLUSÕES}

Com o despejo incorreto do lodo de ETA em corpos d'água, fica evidente que o mesmo afeta a natureza negativamente;

A caracterização físico-químicabiológica do lodo gerado na ETA do SAAE de Formiga - MG mostrou que esse resíduo é altamente poluidor, não se enquadrando à legislação pertinente;

Em função do atual destino dado para o lodo da ETA do SAAE de Formiga MG, faz-se urgente planejar sua destinação correta, sendo sua destinação para aterros sanitários a opção mais viável.

\section{REFERÊNCIAS}

ACHON, C.L.; BARROSO, M.M.; CORDEIRO, J.S. Resíduos de estações de tratamento de água e a ISO 24512: desafio do saneamento brasileiro. Artigo Técnico, Eng. Sanit. Ambient, v.18, n.2, 2013, p. 115-122.

AMÂNCIO, D. V. Caracterização do lodo gerado numa estação de tratamento de água: influência da sazonalidade. Formiga: UNIFOR-MG, 2012. Trabalho de Conclusão de Curso (Engenharia Ambiental e Sanitária). Centro Universitário de Formiga, 2012.

AMERICAN PUBLIC HEALTH ASSOCIATION - APHA. Standard Methods for The Examination of Water and Wastewater. 21 ed. Washington: APHA, 2005.

ANDREOLI, C. V. Resíduos sólidos do saneamento: processamento, reciclagem e disposição final. Projeto PROSAB 2. Rio de Janeiro: RiMa, ABES, 2001. 
AZEVEDO, F.A. Toxicologia do

mercúrio. São Carlos: Rima, 2003.

BARBOSA, R. M.; POVINELLI, J.; ROCHA, O.; ESPÍNDOLA, E.L.G.: A toxicidade de despejos (lodos) de estações de tratamento de água à Daphnia similis (cladocera, crustácea). In: XXVII Congresso Interamericano de Engenharia Sanitária e Ambiental, 2000. Anais. Porto Alegre: ABES, 2000. Disponível em: $<$ http://www.bvsde.paho.org/bvsaidis/trata gua/ii-008.pdf>. Acesso em 03 set. 2017.

BARROSO, M. M.; CORDEIRO, J. S. Problemática dos metais nos resíduos gerados em estações de tratamento de água. In: XXI Congresso Brasileiro de Engenharia Sanitária, 2001. Anais. João Pessoa: ABES, 2001. 1 CD-ROM.

BOTERO, W. G. Caracterização de lodo gerado em estações de tratamento de água: perspectivas de aplicação agrícola. Quim. Nova, v. 32, n. 8, p. 2018-2022, 2009.

CERQUEIRA, C.C.C.; FERNANDES, M.N. Gill tissue recovery after copper exposure and blood parameter responses in the tropical fish Prochilodus scrofa. Ecotoxicol. Ecotoxicol. Environ. Safety, 52: 83-91. 2002.

\section{CONSELHO NACIONAL DO MEIO} AMBIENTE - CONAMA. Resolução $\mathbf{n}^{\circ}$ 430. 2011. Dispõe sobre condições e padrões de lançamento de efluentes, complementa e altera a Resolução 357, de 17 de março de 2005.

\section{ENVIRONMENT PROTECTION}

AGENCY - EPA. Advanced photochemical oxidation processes. EPA/625/R-98/004, 1998a.

Method 3050B. Acid digestion of sediments, sludges and soils. Revision 2, U.S.: EPA., 1996.
Method 6045D. Soil and waste

pH. Revision 4, U.S.: EPA., 2004.

Methods for chemical analysis of water and wastes. EPA 60014-79-020, Washington D.C., 1983. Método 6020A (SW-846):

Espectrometria de massa plasmática acoplada indutivamente, Revisão 1. U.S.: EPA, 1998b.

FERREIRA, D. F. SISVAR: um programa para análises e ensino de estatística.

Revista Symposium, v.6, p.36-41, 2008.

GONÇALVES, F.R. Influência dos mecanismos de coagulação da água bruta na reciclagem de coagulantes em lodos de estações de tratamento de água. In: XIX Congresso Brasileiro de Engenharia Sanitária e Ambiental. Anais. Foz do Iguaçu: ABES, 1997.

HANSEN, J.A.; LIPTON, J.; WELSH, P.G.; MORRIS, J.; CACELA, D.; SUEDKAMP, M.J. Relationship between exposure duration, tissue residues, growth, and mortality in rainbow trout (Oncorhynchus mykiss) juveniles subchronically exposed to copper. Aquat. Toxicol., 58: 175-188. 2002.

HEATH, A.G. Changes in tissue adennylates and water content of bluegill, Lepomis macrochiurus exposed to copper. J. Fish Biol., 24: 289-299. 1984. . Water pollution and fish physiology. 2.ed. CRC Press, Lewis publishers. 342p. 1995.

KARAN, V.; VITOROVIC, S.; TUTUNDSIE, V.; POLESKSIE, V. Functional enzymes activity and gill histology of carp after copper sulfate exposure and recovery. Ecotoxicol. Environ. Safety, 40: 49-55. 1998. 
KLAASSEN, C.D. Metais pesados e seus antagonistas. In: Gilman, A.G.; Goodman, L.S. E Gilman, A. - As Bases

Farmacológicas da Terapêutica, 8. ed. Rio de Janeiro: Editora Guanabara Koogan S.A., p. 1061 - 1065. 1991.

LAURÉN, D.J.; MCDONALD, D.G. Acclimation to copper by rainbow trout, Salmo gairdneri: physiology. Can. J. Fish. Aquat. Sci., 44: 99-104. 1987.

LEAL, L.R. Uso de hidróxido de cálcio com sulfato de alumínio ferroso para melhoria da floculação e decantação nas águas tratadas pelo SAAE de FormigaMG. Formiga: UNIFOR, 2009. (Trabalho de conclusão de curso - Engenharia Ambiental)

LIMA, R.S.R.; LIMA, R.; OKANO, N.H. Saneamento ambiental. Curitiba: CREAPR, 2016. Disponível em:

$<$ http://177.92.30.55/ws/wpcontent/uploads/2016/12/saneamentoambiental.pdf $>$. Acesso em 03 set. 2017.

MAZON, A.F.; CERQUEIRA, C.C.C.; MONTEIRO, E.A.S.; FERNANDES, M.N. Acute copper exposure in freshwater: morphological and physiological effects. In: VAL, A.L.; ALMEIDA-VAL, V.M. (Eds). Biology of tropical fishes. Instituto Nacional de Pesquisa da Amazônia/Universidade do Amazonas, Manaus, Amazonas. p. 263275. 1999.

MAZON, A.F.; MONTEIRO, E.A.S.; PINHEIRO, G.H.D.; FERNANDES, M.N. Hematological and physiological changes induced by short-term exposure to copper in freshwater fish, Prochilodus scrofa.

Braz. J. Biol., 63 (2): 621-631. 2002.

MCGEER, J.C.; SZEBEDINSZKY, C.; MCDONALD, D.G.; WOOD, C.M. Effects of chronic sublethal exposure to waterborne $\mathrm{Cu}, \mathrm{Cd}$ or $\mathrm{Zn}$ in rainbow trout 1: iono-regulatory disturbance and metabolic costs. Aquat. Toxicol., 50: 231243. 2000a.

Effects of chronic sublethal exposure to waterborne $\mathrm{Cu}, \mathrm{Cd}$ or $\mathrm{Zn}$ in rainbow trout 2: tissue specific metal accumulation. Aquat. Toxicol., 50: 245256. $2000 \mathrm{~b}$.

MINISTÉRIO DA AGRICULTURA, PECUÁRIA E ABASTECIMENTO MAPA. Instrução Normativa SDA No 17. Diário Oficial da União - Seção 1, n. 99, 24 mai. 2007. Métodos analíticos oficiais para análise de substratos para plantas e condicionadores de solo. Brasília: MAPA, 2007.9p.

NUSSEY, G.; VAN VUREN, J.H.J.; DU PREEZ, H.H. Effect of copper on blood coagulation of Oreochromis mossambicus (Cichlidae). Comp. Biochem. Physiol. C, 111: 369-380. 1995a.

Effect of copper on the haematology and osmoregulation of Mozambique tilapia, Oreochromis mossambicus (Cichlidae). Comp. Biochem. Physiol. C, 111: 359-367. 1995b.

OLIVEIRA, I.Y.Q. Gerenciamento do lodo de estação de tratamento de água em Mato Grosso do Sul: uma análise crítica. Campo Grande: UFMS, 2016. 67 p. Trabalho de Conclusão de Curso (Mestrado Profissional) - Universidade Federal de Mato Grosso do Sul, 2016.

RICHTER, C.A.; AZEVEDO NETTO, J.M. Tratamento de Água. São Paulo, 2003. 330p.

RODRIGUES, F. N. Caracterização dos resíduos da estação de tratamento de água da UFLA e aproveitamento na confecção de tijolos de solo-cimento. Lavras: UFLA, 2015. 117 p : il. Dissertação (mestrado acadêmico) Universidade Federal de Lavras, 2015. 
ROMÉO, M.; BENNANI, N.; GNASSIABARELLI, M.; LAFAURIE, M.; GIRARD, J.P. Cadmium and copper display different responses towards oxidative stress in the kidney of the sea bass Dicentrarchus labrax. Aquatic. Toxicol., 48: 185-194. 2000.

SANTOS, L. F.; GARCIA; S. R. Início e fim da estação chuvosa no Estado de Minas Gerais: comparação de duas metodologias diferentes. Revista

Brasileira de Meteorologia, v. 31, n. 1, 92-104, 2016. DOI:

http://dx.doi.org/10.1590/0102778620150017

SILVA M.N.; XAVIER, P.H.F.S.

Avaliação dos teores de alumínio no efluente da ETA-Anápolis-GO. In: $48^{\circ}$ Congresso Brasileiro de Química. Rio de Janeiro, 2008. Disponível em:

$<$ http://www.abq.org.br/cbq/2008/trabalho s/5/5-507-4831.htm $>$. Acesso em: $02 \mathrm{de}$ Nov. de 2012.

SILVA, D. M. L. Dinâmica de nitrogênio em microbacias no Estado de São Paulo. Centro de Energia Nuclear na Agricultura da Universidade de São Paulo, 2005. Tese de Doutoramento.

SUALL INDÚSTRIA E COMÉRCIO LTDA. Dispónivel em: $<$ www.suall.com.br $>$. Acesso em: 30. Nov 2012.

UNIVERSIDADE FEDERAL DE CAMPINA GRANDE - UFCG.

Monitoramento da qualidade da água na bacia hidrográfica do rio cabelo.

Disponível em: <www.deag.ufcg.edu.br $>$. Acesso em: 1. Dez. 2012.

VIANA, C.C.; RODRIGUES, F.N.; RIBEIRO, K.D. Caracterização físicoquímica e biológica do lodo gerado em Estação de Tratamento de Água (ETA). In: $4^{\circ}$ Congresso Internacional de Tecnologias para o Meio Ambiente. Anais. Bento Gonçalves: UCS, 2014. Disponível em: $<$ https://siambiental.ucs.br/congresso/getA rtigo.php?id=388\&ano=_quarto $>$. Acesso em 03 set. 2017.

WINDMÖLLER, C.C. et al. Distribuição e especiação de mercúrio em sedimentos de áreas de garimpo de ouro do Quadrilátero Ferrífero (MG). Química Nova, v. 30, n. 5, p. 1088-1094, 2007. 